\section{The Missing Side of Acculturation: How Majority-Group Members Relate to Immigrant and Minority-Group Cultures}

\author{
Jonas R. Kunst ${ }^{1} \mathbb{D}$, Katharina Lefringhausen ${ }^{2}$, David L. Sam ${ }^{3}$, \\ John W. Berry ${ }^{4,5}$, and John F. Dovidio ${ }^{6}$ \\ ${ }^{1}$ Department of Psychology, University of Oslo; ${ }^{2}$ Centre for Applied Linguistics, University of Warwick; \\ ${ }^{3}$ Faculty of Psychology, University of Bergen; ${ }^{4}$ Department of Psychology, Queen's University; \\ ${ }^{5}$ Higher School of Economics, International Center for Sociocultural Research, Moscow, Russian Federation; \\ and ${ }^{6}$ Department of Psychology, Yale University
}

Current Directions in Psychological Science

$1-10$

(C) The Author(s) 2021

(c) (i)

Article reuse guidelines:

sagepub.com/journals-permissions DOI: 10.1177/09637214211040771 www.psychologicalscience.org/CDPS (S)AGE

\begin{abstract}
In many countries, individuals who have represented the majority group historically are decreasing in relative size and/or perceiving that they have diminished status and power compared with those self-identifying as immigrants or members of ethnic minority groups. These developments raise several salient and timely issues, including (a) how majority-group members' cultural orientations change as a consequence of increasing intercultural contact due to shifting demographics; (b) what individual, group, cultural, and socio-structural processes shape these changes; and (c) what the implications of majority-group members' acculturation are. Although research across several decades has examined the acculturation of individuals self-identifying as minority-group members, much less is known about how majority-group members acculturate in increasingly diverse societies. We present an overview of the state of the art in the emerging field of majority-group acculturation, identify what is known and needs to be known, and introduce a conceptual model to guide future research.
\end{abstract}

\title{
Keywords
}

acculturation, integration, intergroup contact, majority group, multiculturalism

Acculturation is the process of cultural and psychological change caused by intercultural contact (Berry, 1980, 2018). Theoretically, it involves mutual accommodation by both individuals self-identifying as minority-group members and those self-identifying as majority-group members. However, research has primarily focused on the cultural changes experienced by people who selfidentify as immigrants or minority-group members ${ }^{1}$ (Sam \& Berry, 2016). In a period of unprecedented demographic changes that are affecting societies globally, understanding how, when, and why majority-group culture is influenced by people who self-identify as immigrants or minority-group members is important and timely.

\section{Minority-Group Acculturation}

Much psychological research on acculturation has drawn on a fourfold model of acculturation (Sam \&
Berry, 2016). Although this model acknowledges withingroup variability, its focus is on systematic betweengroups differences, and it has been applied mainly with respect to orientations to two cultures-minority-group and majority-group cultures. Relevant research shows that people identifying with immigrant or minoritygroup cultures regularly use four basic acculturation strategies. Individuals who follow the strategy of integration (the most preferred strategy) maintain their heritage culture while also adopting the mainstream majority culture of their society of residence. Those pursuing the strategy of assimilation give up their heritage culture in favor of the mainstream culture. People following the strategy of separation maintain their heritage culture while rejecting the mainstream culture.

\section{Corresponding Author:}

Jonas R. Kunst, Department of Psychology, University of Oslo Email: j.r.kunst@psykologi.uio.no 
Finally, those who neither maintain their heritage culture nor adopt the mainstream culture are employing the strategy of marginalization.

The much more limited acculturation research on majority groups has primarily considered majoritygroup members' resistance to changes in their culture and their expectations and preferences concerning how people who self-identify as immigrants or minoritygroup members should acculturate (Bourhis et al., 1997; Zárate et al., 2012). Research rarely considers the acculturative changes experienced by majority-group members.

\section{Majority-Group Acculturation}

Drawing on definitions applied primarily to minoritygroup acculturation (e.g., Berry, 2018; Redfield et al., 1936), we define majority-group acculturation as the cultural and psychological changes that current or former majority-group members experience and the cultural styles they adopt as a result of contact with people self-identifying as immigrants or ethnic minority-group members living in the same society. Majority-group acculturation is not simply the recognition of minoritygroup culture. Rather, it involves the genuine incorporation of aspects of minority-group culture into majority-group members' default cultural repertoire and ultimately leads to changes in the mainstream culture at the societal level.

One central way in which the concept of majoritygroup acculturation differs from how minority-group acculturation has commonly been conceptualized is that it involves cultural and psychological changes stimulated in concert by contact with members of multiple, diverse groups. That is, current or former majoritygroup members who have contact with members of different minority groups over time may adopt elements of various ethnic cultures to different degrees. Thus, majority-group acculturation focuses on the influence of multiple heritages, which are present in many contemporary, highly diverse contexts of acculturation (Doucerain, 2019; Doucerain et al., 2013).

Majority-group acculturation can occur at an individual level, as changes in personal practices, values, and identity (Schwartz et al., 2010), and/or at a societal level, for example, as changes in language or norms. At the individual level, as majority-group members repeatedly interact with minority-group members, they may engage in new cultural practices (e.g., non-Jews may celebrate Hanukkah, non-Muslims may fast together with their friends during Ramadan), prefer different food products (e.g., halal products), or explore and even convert to different religions. At the societal level, through intercultural friendships and romantic partnerships, norms for intercultural contact can change (Christ et al., 2014). In addition, majority-group members, and particularly those of younger generations, may adopt new linguistic expressions and pronunciations, which at the societal level sometimes results in entirely new dialects. Majority-group acculturation can also create changes in the way a group and its members perceive their defining characteristics. Such changes can concern the specific nature of an identity: For example, a significant percentage of residents of New Mexico identify with the Hispanos culture of the state, a historical blend of Spanish and U.S. cultures. Majoritygroup acculturation can also affect the structure of cultural identity, leading to more complex cultural identities (e.g., a more multicultural identity). Thus, through the process of majority-group acculturation, the way people identify with the mainstream culture may become more inclusive, complex, and permeable (Lefringhausen et al., 2021).

Current evidence suggests that majority-group acculturation differs in important ways from minority-group acculturation. People self-identifying as members of majority groups tend to adopt only two of the four strategies commonly observed among those self-identifying as immigrants or minority-group members. As Figure 1 shows, prior studies have indicated that a sizable percentage of majority-group members follow the strategy of integration, adopting elements of immigrants' and other minority groups' cultures while also maintaining their majority-group culture. However, a considerable percentage of majority-group members follow the strategy of separation, orienting themselves toward their majority-group culture while rejecting the culture of individuals self-identifying as immigrants or minority-group members. Assimilation and marginalization seem to be rarely used by majority-group members.

In further contrast to work with people self-identifying as immigrants or minority-group members, the studies summarized in Figure 1 revealed that a substantial percentage of majority-group members show no clear-cut preference for any of the four previously identified strategies. This "diffuse strategy" is, in fact, one of the most common patterns of majority-group acculturation.

\section{Distinctive Processes in Majority- Group Members' Acculturation}

There are at least two elements that critically distinguish majority-group acculturation from minority-group acculturation. First, majority-group acculturation requires changes to the traditional culture of a society and its status quo. Second, the majority group typically has more power (i.e., social, political, and economic 


\section{Lefringhausen (2015)}

U.S. Citizens Without Personal Migration History $(N=208)$

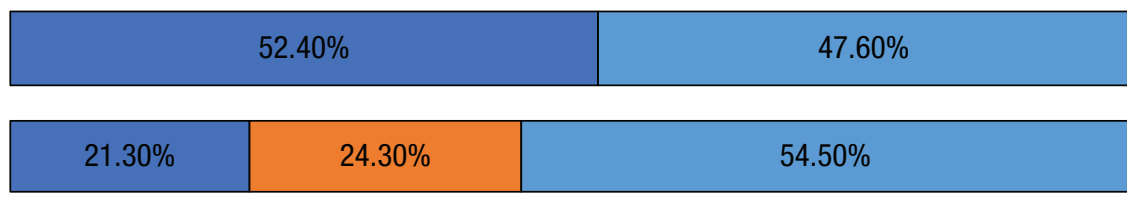

Indians Without Migration History $(N=57)$

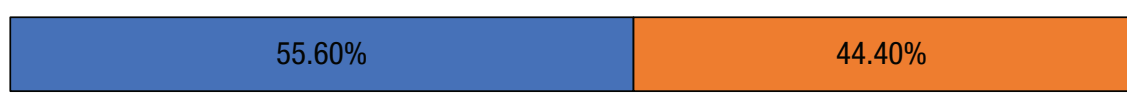

Chinese Without Migration History $(N=54)$

\section{Lefringhausen \& Marshall (2016)}

\section{U.S. Citizens Without Personal Migration History $(N=218)$}

Britons Without Migration History $(N=103)$

Germans Without Migration History $(N=111)$

U.S. Citizens Without Personal Migration

History $(N=200)$
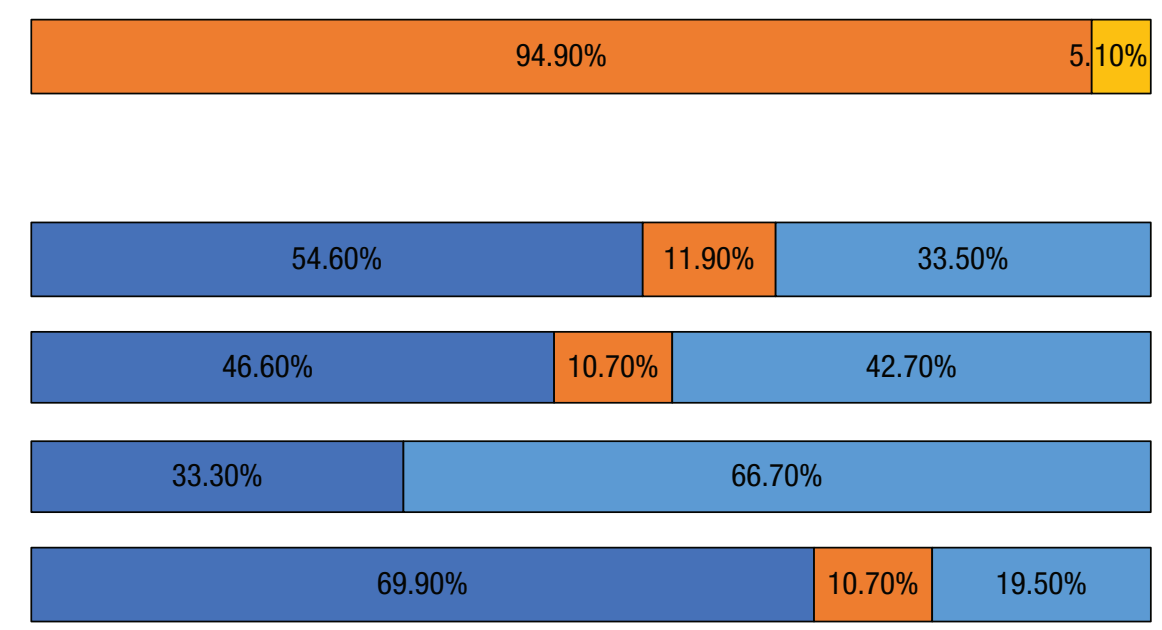

Indians Without Migration History $(N=104)$

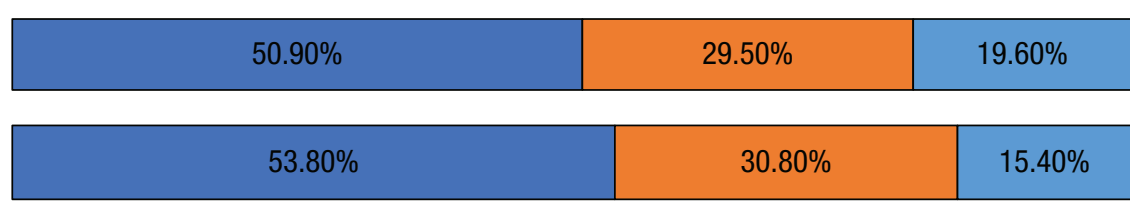

Haugen \& Kunst (2017)

Ethnic Norwegians $(N=185)$

\begin{tabular}{|l|l|l|}
\hline $31.10 \%$ & $37.20 \%$ & $31.70 \%$ \\
\hline
\end{tabular}

Kunst et al. (2021)

White Americans $(N=301)$

\begin{tabular}{|l|l|l|l|}
\hline $20.30 \%$ & $21.90 \%$ & $22.90 \%$ & $34.90 \%$ \\
\hline
\end{tabular}

Lefringhausen et al. (2021)

White English $(N=62)$

\begin{tabular}{|c|c|c|c|}
\hline $22.20 \%$ & $33.30 \%$ & \multicolumn{2}{|c|}{$44.40 \%$} \\
\hline & & $23.60 \%$ & $11.80 \%$ \\
\hline
\end{tabular}

White English $(N=220)$

Fig. 1. The acculturation strategies followed by majority-group members in a series of studies. For each sample, the graph shows the distribution of participants across the four strategies commonly studied in immigrant and other minority groups: integration, maintaining majority-group culture while also adopting aspects of immigrant and minority-group cultures; separation, maintaining majority-group culture while rejecting immigrant and minority-group cultures; assimilation, giving up majority-group culture in favor of immigrant or minoritygroup cultures; and marginalization, rejecting both cultures. In addition, in most studies, a sizable percentage of individuals (the "diffuse" cluster) reported no clear preference for any of these four acculturation strategies. "Without personal migration history" refers to research participants who were born in the country of investigation and thus had no personal experiences of migrating to that country. "Without migration history" refers to participants who indicated that neither they nor their families had a migration history. 
power) than immigrants or minority-group members (Berry, 1980). People have a psychological bias to adhere to the status quo that is known and understood rather than to pursue change, which is often uncertain. Change stimulated by the increasing presence and potential influence of people self-identifying as immigrants or minority-group members is commonly perceived as a threat to the higher status of the majority group (Verkuyten, 2006) and leads its members to reinforce traditional values (Craig \& Richeson, 2014). These processes have implications for both when and how majority-group members acculturate.

There are several conditions that may increase majority-group members' willingness to change their own group's culture (see Table 1). At the level of individual differences, more open-mindedness, stronger growth values (e.g., caring about the welfare of all people), and less conscientiousness are associated with greater adoption of cultures of individuals self-identifying as immigrants or minority-group members. Moreover, having more frequent intercultural contact (particularly, higher-quality contact), being more culturally sensitive, and perceiving immigration more as an enrichment than as a threat are associated with more cultural adoption. At the group and cultural level, having a stronger global identity (e.g., identifying with a common humanity) and being more ethnorelativist (i.e., showing high cultural empathy and tolerance), as well as being less ethnocentric and nationalistic, are linked to greater cultural adoption.

Many of these factors show the opposite relationship with majority-group members' maintenance of their majority culture (see Table 1). At the individual level, greater openness and having more intergroup contact are related to less cultural maintenance, and perceiving immigrants more as a threat, greater emotionality, and greater extraversion are related to more. At the group level, having less global identity and holding a stronger national identification are related to more majorityculture maintenance. Ethnocentrism was not significantly associated with maintenance of majority-group culture in previous research, which suggests that this orientation may be an attempt to conserve one's culture during a time of change rather than a reflection of a prejudiced mind.

\section{Conceptual Model and Future Research Directions}

Although the fourfold model of acculturation explains considerable variation in majority-group members' acculturation, the recurrent diffuse cluster suggests that further refinement in conceptualizing majority-group acculturation is needed. Accordingly, we present a model of majority-group acculturation in Figure 2. Grounded in processes identified in the existing literature, the model includes individual-level factors and interpersonal experiences and their relationship to adaptation to culturally diverse environments. The model also suggests concrete paths to extend the literature on this topic in a theory-based way by taking a multilevel perspective that further considers group and cultural characteristics and socio-structural influences. Our model assumes that each majority group's acculturation needs to be understood within its unique context (the specificity principle of acculturation; Bornstein, 2017) but that groups and contexts also share commonalities. Therefore, some similar processes are expected to influence and respond to majority-group members' acculturation across contexts, whereas others may be context dependent. The factors identified at each level are intended to be illustrative, not an exhaustive list.

\section{Individual level}

At the core of the model is majority-group members' individual-level acculturation, that is, (a) the degree to which they adopt the culture of people who selfidentify as immigrants or minority-group members and (b) the degree to which they maintain their majoritygroup culture (see Fig. 2). Seminal acculturation research (Schwartz et al., 2010) indicates that this process can vary by life domain.

Also at the individual level of our model are individual differences (e.g., personality traits or values, such as open-mindedness) and intergroup perceptions and attitudes (e.g., viewing diversity as a benefit rather than a threat, perceiving multiculturalism as normative in one's society; Watters et al., 2020). These factors can directly or indirectly influence majority-group acculturation. For example, by facilitating more and higherquality intergroup contact (Jackson \& Poulsen, 2005), they can lead to more adoption of another culture and less maintenance of the mainstream culture. Certain individual differences can also reduce majority-group members' likelihood of adopting other cultures: For example, prejudiced majority-group members may experience cultural exchanges as superficial and nonintimate (Boin et al., 2021), which reduces the impact of contact on acculturation.

The model also highlights reciprocal, potentially cyclical relationships at the individual level. For example, not only may positive intergroup attitudes lead to greater majority-group acculturation, but also greater acculturation may in turn lead to developing more positive perceptions and attitudes as well as adoption of 
Table 1. Variables Associated With Majority-Group Members' Adoption of Other Cultures and Maintenance of Their Majority Culture

\begin{tabular}{|c|c|c|c|}
\hline \multirow[b]{2}{*}{ Variable } & \multicolumn{2}{|c|}{ Association } & \multirow[b]{2}{*}{ Reference } \\
\hline & $\begin{array}{l}\text { With adoption } \\
\text { of other cultures }\end{array}$ & $\begin{array}{l}\text { With maintenance of } \\
\text { the majority culture }\end{array}$ & \\
\hline \multicolumn{4}{|l|}{ Social identity } \\
\hline Global identity & + & - & Lefringhausen et al. (2021) \\
\hline Ethnorelativism & + & + & Lefringhausen and Marshall (2016) \\
\hline National identity & - & + & Lefringhausen et al. (2021) \\
\hline Ethnocentrism & - & n.s. & Lefringhausen and Marshall (2016) \\
\hline National identity & n.s. & + & Lefringhausen and Marshall (2016) \\
\hline \multicolumn{4}{|l|}{ Intergroup relations } \\
\hline Intergroup contact & + & NA & Lefringhausen et al. (2020) \\
\hline Intergroup contact & + & - & Lefringhausen et al. (2021) \\
\hline Positive feelings toward immigrants & + & - & Lefringhausen et al. (2021) \\
\hline Intercultural sensitivity & + &,+ n.s. ${ }^{\mathrm{a}}$ & Lefringhausen and Marshall (2016) \\
\hline Perceived enrichment & + &,- n.s. ${ }^{\mathrm{a}}$ & Lefringhausen et al. (2021) \\
\hline Perceived threat & - & + & Haugen and Kunst (2017) \\
\hline Perceived threat & - & NA & Lefringhausen et al. (2020) \\
\hline Perceived threat & - & + & Lefringhausen et al. (2021) \\
\hline Perceived discrimination & - & + & Haugen and Kunst (2017) \\
\hline \multicolumn{4}{|l|}{ Personality and values } \\
\hline Openness & + & - & Kunst et al. (2021) \\
\hline Growth value & + & NA & Lefringhausen et al. (2020) \\
\hline Conscientiousness & - & n.s. & Kunst et al. (2021) \\
\hline Extraversion & n.s. & + & Kunst et al. (2021) \\
\hline Emotionality & n.s. & + & Kunst et al. (2021) \\
\hline
\end{tabular}

Note: $+=$ positive significant relationship; $-=$ negative significant relationship; $n . s .=$ nonsignificant relationship; NA $=$ relationship not reported.

${ }^{a}$ Effects from more than one study were reported.

values that promote more and higher-quality contact, which can ultimately promote further acculturation.

At the individual level, majority-group members' acculturation may influence their psychological adaptation (e.g., well-being), their sociocultural adaptation (e.g., competence in navigating culturally diverse contexts), and their cognitive adaptation (e.g., creativity, flexible thinking). Both adoption of minority-group culture and maintenance of the majority culture may be adaptive depending on the context. For instance, although adoption of minority perspectives may facilitate majority-group members' communication with ethnic out-group members, maintaining the majority heritage culture may offer benefits in interactions with other majority-group members. However, given new meta-analytic insights into the limited influence of acculturation on adaptation among minority groups (Bierwiaczonek \& Kunst, 2021) and inconsistent findings in research on majority-group acculturation, we have represented the connection between acculturation and adaptation with a striped arrow in Figure 2. To the best of our knowledge, only one study found, in one of its samples, that adopting elements from other cultures correlated with higher life satisfaction and less acculturative stress among majority-group members (Lefringhausen \& Marshall, 2016). By contrast, several studies have shown that maintaining their majority culture was positively linked to majority-group members' life satisfaction and self-esteem (Haugen \& Kunst, 2017; Lefringhausen \& Marshall, 2016). These latter findings are consistent with general theorizing in the acculturation and ethnic-identity literature suggesting that a stable and secure attachment to one's own group is related to more positive psychological adaptation (Phinney et al., 1997). Thus, the fact that greater perceived threat is related to more cultural maintenance (see Table 1) suggests that majority-group members may increase their engagement in their heritage culture to counter uncertainty, just as minority-group members do (Branscombe et al., 1999).

Sociocultural adaptation can involve the acquisition of new cultural schemas that facilitate cultural "fluency" 


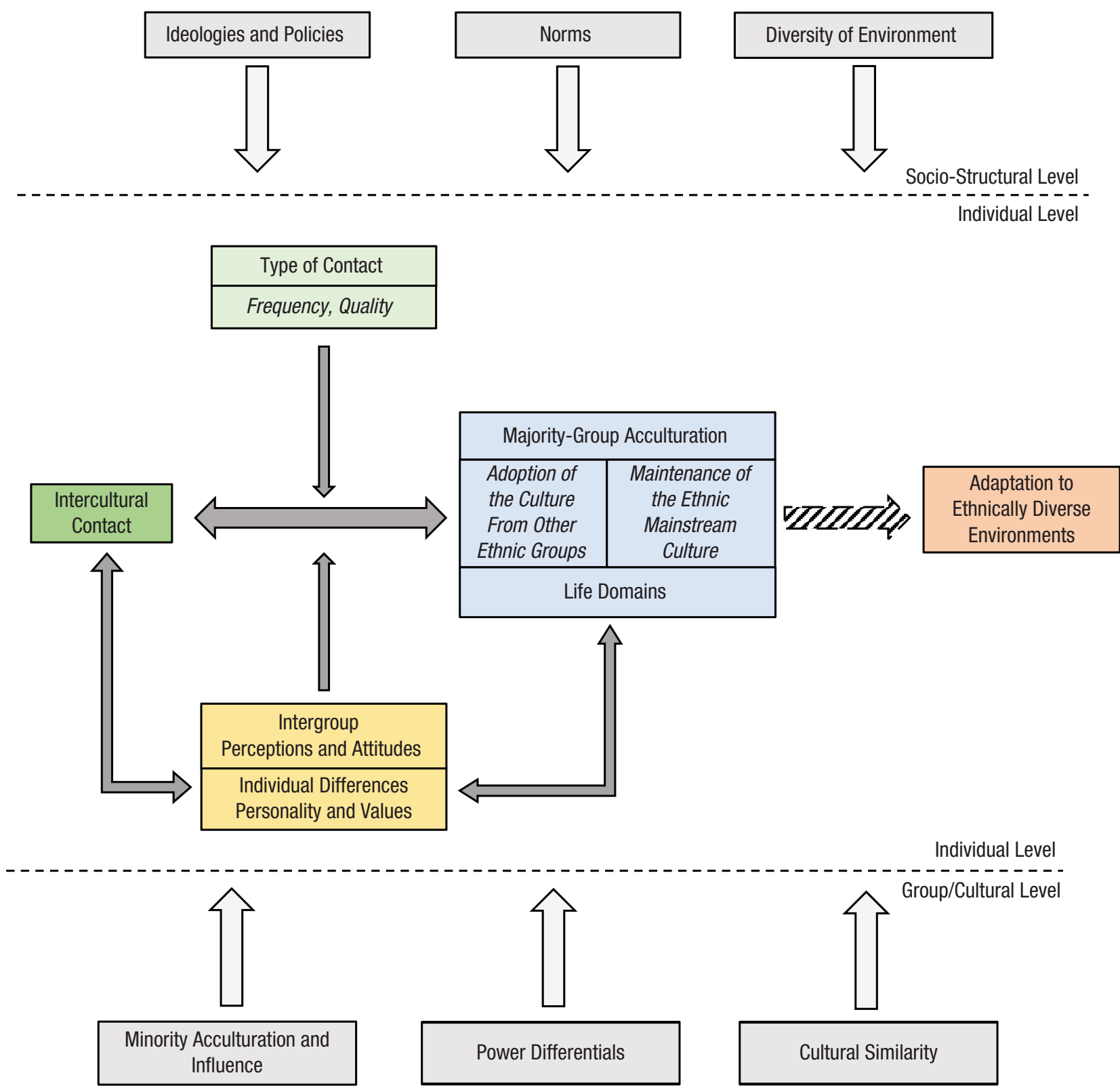

Fig. 2. Conceptual model of majority-group members' acculturation. At the individual level (dark-gray arrows), acculturation starts with the process of intercultural contact between majority-group members and individuals self-identifying as immigrants or minoritygroup members within a shared society. The frequency and quality of this contact, majority-group members' intergroup perceptions and attitudes, and majority-group members' individual differences (e.g., values, traits) influence the extent to which the intercultural contact leads them to adopt immigrant or minority-group cultures and also the degree to which they maintain their majority-group culture, which can vary by life domain. How majority-group members acculturate may further influence how they feel (i.e., psychological adaptation), how efficiently they navigate culturally diverse contexts (i.e., sociocultural adaptation), and their creativity and flexible thinking (i.e., cognitive adaptation). The striped arrow highlights the fact that there has been limited previous work on this latter process. The individual-level processes are likely to interact further with group and cultural factors and with socio-structural factors (light-gray arrows).

(Doucerain, 2019). As majority-group members adopt values and worldviews from minority-group members, they may experience more fluent interactions in culturally diverse environments. This change may involve processes at a very basic cognitive level, including situational perceptions and automatic affective responses. For instance, majority-group members' adoption of new moral values can alter their perceptions of, and spontaneous emotional reactions to, different situations. 


\section{Group and cultural level}

Our model also considers processes at the group and cultural level (see Fig. 2). Status differences between the majority and minority groups are one such factor. Societies are universally structured by group hierarchy; high-power groups have more access to resources than low-power groups do, and they often have control over low-power groups (Sidanius et al., 2016). Because people, particularly those who strongly endorse group hierarchies, tend to see group outcomes as zero-sum (a gain for another group is seen as a loss for one's own group), majority-group members may be resistant to adopt the culture of low-status minority groups (Guimond et al., 2013; Verkuyten, 2006).

However, when majority-group members perceive that the inclusion of other groups' values, traditions, ideas, or skills makes the collective group stronger, they may be more willing to adopt various aspects that "newcomers" bring with them (Rink \& Ellemers, 2008). This may especially be the case when majority-group members perceive that they share a common in-group identity with immigrants or minority-group members (e.g., an inclusive national identity; Gaertner et al., 2016; Rink \& Ellemers, 2008).

Members of a high-power majority group may indeed adopt aspects of the cultures of individuals selfidentifying as immigrants or minority-group members but in a superficial way that reflects exertion of majoritygroup dominance in the form of cultural appropriation (Rogers, 2006) rather than "true" acculturation (i.e., a deeper, constructive engagement with new cultural content that may ultimately be adopted permanently). Although majority-group members may not acknowledge the role of dominance in this process, minority-group members often perceive cultural appropriation as a threat to their group's distinctiveness, which adversely affects intergroup relations (Mosley \& Biernat, 2020). Hence, the impact of majority-group members' acculturation depends critically on its underlying motivations.

Motivations for maintaining different groups' distinctiveness appear to be particularly strong in contexts in which the social group in power constitutes a numerical minority in the society-historically in South Africa and currently in countries such as the United Arab Emirates. In these contexts, high-power numerical-minority groups can be expected to show little voluntary adoption of the low-power numerical-majority group's culture (Berry, 2017). In other words, where power and numerical size are dissociated, motivations to maintain, reinforce, or enhance power differentials play a particularly strong role, limiting the acculturation of members of the high-power, yet numerical-minority, group.

\section{Socio-structural level}

Societal ideologies, policies, and norms are likely to play an important role in majority-group acculturation. Societies that favor assimilation as an acculturation strategy, either by norms or by formal policy (Sam \& Berry, 2016), are unlikely to encourage majority-group acculturation because immigrants and minority-group members are expected to adopt the standards of the majority-group culture, not vice versa. By contrast, multicultural societies that codify the accommodation of elements of different cultures in formal policy, such as through multilingual education, holiday celebrations, or other expressions of cultural traditions, are more likely to exhibit mutual acculturation and engage more actively and constructively with other cultures (Sam \& Berry, 2016).

\section{Future directions: cross-level research}

Our model has the potential of suggesting cross-level research directions. Considering majority-group acculturation as involving both individual-level and groupand cultural-level processes helps illuminate how people self-identifying as immigrants or minority-group members can actively influence the culture of majoritygroup members during intercultural exchanges. Applying the minority-influence framework (Harkins et al., 2017) to acculturation offers insights into how minoritygroup members can actively facilitate majority-group acculturation and suggests group- and cultural-level factors (e.g., relative group size) that might moderate this effect.

Appreciating the potentially reciprocal group influences in the dynamics of acculturation also highlights the importance of the alignment between the preferred acculturation strategies of minority groups and the majority group (Bourhis et al., 1997), as well as of studying the mutual changes that may result (Berry, 2017; Horenczyk et al., 2013). For example, when the shared preference is integration, minority and majority groups may reciprocally adopt cultural elements from each other, which may ultimately lead to a new blended culture (Ward et al., 2018). The diffuse acculturation strategy repeatedly observed in previous work (see Fig. 1) may reflect an orientation toward such a culture shift.

Future qualitative and mixed-methods investigations may offer valuable insights into the everyday and longterm dynamics of majority-group members' acculturation. For instance, it is possible that majority-group members have clearer acculturation preferences in some domains (e.g., socialization, friendships) than others (e.g., traditions, values). Moreover, the diffuse 
cluster likely reflects not just one but rather several cultural styles that a detailed focus on group, cultural, and structural processes may help distinguish.

Cultural similarity, located in the group and cultural level of our model, may also systematically influence majority-group acculturation at the individual level (Schwartz et al., 2010). Similarity between majority and minority cultures may increase the likelihood that they evolve to become blended cultures, a process that involves significant majority-group cultural change. Conversely, dissimilarity between the cultures increases the probability that members of both minority and majority groups will perceive that the culture of the out-group threatens their own cultural values, symbols, and identities (Stephan et al., 2016). Thus, majoritygroup members may selectively choose to adopt the culture from more similar immigrant or minority-groups at a higher rate.

Individual-level processes can also operate in combination with socio-structural factors, such as the diversity of the environment. For majority-group members, adopting the ways (or cultural schemas) of other cultures may lead to more smooth and effective intercultural encounters, thereby reducing acculturative stress (Doucerain, 2019). However, this effect may occur primarily for majority-group members in socially diverse contexts, where being able to interact efficiently with members from other cultural groups is vital, and not in homogeneous majority-group environments. Moreover, mirroring the study of minority-group acculturation, the study of majority-group acculturation has thus far been primarily concerned with individual-level psychological changes. However, it is possible that immigrant and minority-group acculturation and majority-group acculturation occur primarily at different levels even though both individual- and group-level changes are involved in both cases. Among members of immigrant or minority groups, change may occur largely at an individual, psychological level. By contrast, majority-group acculturation may occur mainly at the group or societal level as the content of mainstream culture is modified by the incorporation of new cultural elements.

\section{Conclusion}

As societies rapidly become more diverse, they often become more vulnerable to a range of intergroup tensions. Mutual acculturation-changes in the majority group as well as among immigrant and minority groups-may not only foster greater intergroup harmony but also create more cooperative, productive, and healthy relations between individuals and groups. Greater attention to the study of the dynamics and consequences of majority-group acculturation is timely and potentially conceptually transformative as it defines majority-group members as recipients and individuals self-identifying as immigrants or minority-group members as agents of social change in a globalized world.

\section{Recommended Reading}

Lefringhausen, K., Ferenczi, N., Marshall, T. C., \& Kunst, J. R. (2021). (See References). A recent review of the field of majority-group acculturation and its relation to other frameworks.

Verkuyten, M., Yogeeswaran, K., Mepham, K., \& Sprong, S. (2020). Interculturalism: A new diversity ideology with interrelated components of dialogue, unity, and identity flexibility. European Journal of Social Psychology, 50(3), 505-519. https://doi.org/10.1002/ejsp.2628. An introduction to the concept of "interculturalism," which emphasizes identity flexibility and the formation of new identities as alternatives to multiculturalism.

Ward, C., Ng Tseung-Wong, C., Szabo, A., Qumseya, T., \& Bhowon, U. (2018). (See References). An introduction to "identity styles," such as "hybrid identities," which may be of high relevance to majority-group members, as well as minority-group members.

\section{Transparency}

Action Editor: Robert L. Goldstone

Editor: Robert L. Goldstone

Declaration of Conflicting Interests

The author(s) declared that there were no conflicts of interest with respect to the authorship or the publication of this article.

\section{ORCID iD}

Jonas R. Kunst (DD https://orcid.org/0000-0002-5319-1256

\section{Note}

1. Please note that we use the term "immigrants or minoritygroup members" for simplicity, while acknowledging the heterogeneity within and across minority and immigrant groups.

\section{References}

Berry, J. W. (1980). Acculturation as varieties of adaptation. In A. Padilla (Ed.), Acculturation: Theory, models and some new findings (pp. 9-25). Westview Press.

Berry, J. W. (2017). Mutual intercultural relations. Cambridge University Press.

Berry, J. W. (2018). Theories and models of acculturation. In S. J. Schwartz \& J. Unger (Eds.), The Oxford handbook of acculturation and health (pp. 15-28). Oxford University Press.

Bierwiaczonek, K., \& Kunst, J. R. (2021). Revisiting the integration hypothesis: Correlational and longitudinal meta-analyses demonstrate the limited role of acculturation for cross-cultural adaptation. Psychological Science. Advance online publication. https://doi.org/ 10.1177/09567976211006432 
Boin, J., Rupar, M., Graf, S., Neji, S., Spiegler, O., \& Swart, H. (2021). The generalization of intergroup contact effects: Emerging research, policy relevance, and future directions. Journal of Social Issues, 77(1). 105-131. https://doi .org/10.1111/josi.12419

Bornstein, M. H. (2017). The specificity principle in acculturation science. Perspectives on Psychological Science, 12(1), 3-45. https://doi.org/10.1177/1745691616655997

Bourhis, R. Y., Moïse, L. C., Perreault, S., \& Senecal, S. (1997). Towards an interactive acculturation model: A social psychological approach. International Journal of Psychology, 32(6), 369-386. https://doi.org/10.1080/002075997400 629

Branscombe, N. R., Schmitt, M. T., \& Harvey, R. D. (1999). Perceiving pervasive discrimination among African Americans: Implications for group identification and wellbeing. Journal of Personality and Social Psychology, 77(1), 135-149. https://doi.org/10.1037/0022-3514.77.1.135

Christ, O., Schmid, K., Lolliot, S., Swart, H., Stolle, D., Tausch, N., Al Ramiah, A., Wagner, U., Vertovec, S., \& Hewstone, M. (2014). Contextual effect of positive intergroup contact on outgroup prejudice. Proceedings of the National Academy of Sciences, USA, 111(11), 3996-4000. https:// doi.org/10.1073/pnas.1320901111

Craig, M. A., \& Richeson, J. A. (2014). On the precipice of a "majority-minority" America: Perceived status threat from the racial demographic shift affects White Americans' political ideology. Psychological Science, 25(6), 11891197. https://doi.org/10.1177/0956797614527113

Doucerain, M. M. (2019). Moving forward in acculturation research by integrating insights from cultural psychology. International Journal of Intercultural Relations, 73, 11-24. https://doi.org/10.1016/j.ijintrel.2019.07.010

Doucerain, M. M., Dere, J., \& Ryder, A. G. (2013). Travels in hyper-diversity: Multiculturalism and the contextual assessment of acculturation. International Journal of Intercultural Relations, 37(6), 686-699. https://doi .org/10.1016/j.ijintrel.2013.09.007

Gaertner, S. L., Dovidio, J. F., Guerra, R., Hehman, E., \& Saguy, T. (2016). A common ingroup identity: A categorization-based approach for reducing intergroup bias. In T. Nelson (Ed.), Handbook of prejudice, discrimination, and stereotyping (pp. 433-454). Psychology Press.

Guimond, S., Crisp, R. J., De Oliveira, P., Kamiejski, R., Kteily, N., Kuepper, B., Lalonde, R. N., Levin, S., Pratto, F., Tougas, F., Sidanius, J., \& Zick, A. (2013). Diversity policy, social dominance, and intergroup relations: Predicting prejudice in changing social and political contexts. Journal of Personality and Social Psychology, 104(6), 941-958. https://doi.org/10.1037/a0032069

Harkins, S. G., Williams, K. D., \& Burger, J. M. (2017). The Oxford handbook of social influence. Oxford University Press.

Haugen, I., \& Kunst, J. R. (2017). A two-way process? A qualitative and quantitative investigation of majority members' acculturation. International Journal of Intercultural Relations, 60, 67-82. https://doi.org/10.1016/j.ijintrel .2017 .07 .004
Horenczyk, G., Jasinskaja-Lahti, I., Sam, D. L., \& Vedder, P. (2013). Mutuality in acculturation: Toward an integration. Zeitschrift für Psychologie, 221(4), 205-213. https://doi .org/10.1027/2151-2604/a000150

Jackson, J. W., \& Poulsen, J. R. (2005). Contact experiences mediate the relationship between five-factor model personality traits and ethnic prejudice. Journal of Applied Social Psychology, 35(4), 667-685. https://doi .org/10.1111/j.1559-1816.2005.tb02140.x

Kunst, J. R., Lefringhausen, K., Skaar, S., \& Obaidi, M. (2021). Who adopts the culture of ethnic minority groups? A personality perspective on majority-group members' acculturation. International Journal of Intercultural Relations, 81, 20-28. https://doi.org/10.1016/j.ijintrel.2021.01.001

Lefringhausen, K. (2015). The extended acculturation model for locals: Validation, outcomes, and antecedents [Unpublished doctoral thesis, Brunel University London]. Brunel University Research Archive. https://bura.brunel.ac.uk/ handle/2438/11434

Lefringhausen, K., Ferenczi, N., \& Marshall, T. C. (2020). Selfprotection and growth as the motivational force behind majority group members' cultural adaptation and discrimination: A parallel mediation model via intergroup contact and threat. International Journal of Psychology, 55(4), 532-542. https://doi.org/10.1002/ijop.12620

Lefringhausen, K., Ferenczi, N., Marshall, T. C., \& Kunst, J. R. (2021). A new route towards more harmonious intergroup relationships in England? Majority members' proximalacculturation. International Journal of Intercultural Relations, 82, 56-73. https://doi.org/10.1016/j.ijintrel.2021 .03 .006

Lefringhausen, K., \& Marshall, T. C. (2016). Locals' bidimensional acculturation model: Validation and associations with psychological and sociocultural adjustment outcomes. Cross-Cultural Research, 50(4), 356-392. https:// doi.org/10.1177/1069397116659048

Mosley, A. J., \& Biernat, M. (2020). The new identity theft: Perceptions of cultural appropriation in intergroup contexts. Journal of Personality and Social Psychology. Advance online publication. https://doi.org/10.1037/ pspi0000327

Phinney, J. S., Cantu, C. L., \& Kurtz, D. A. (1997). Ethnic and American identity as predictors of self-esteem among African American, Latino, and White adolescents. Journal of Youth and Adolescence, 26(2), 165-185. https://doi .org/10.1023/A:1024500514834

Redfield, R., Linton, R., \& Herskovits, M. J. (1936). Memorandum for the study of acculturation. American Anthropologist, 38(1), 149-152. https://doi.org/10.1525/aa.1936 .38.1.02a00330

Rink, F., \& Ellemers, N. (2008). Diversity, newcomers, and team innovation: The importance of a common identity. In K. W. Phillips (Ed.), Research on managing groups and teams: Vol. 11. Diversity and groups (pp. 221-243). Emerald Group Publishing. https://doi.org/10.1016/ S1534-0856(08)11010-6

Rogers, R. A. (2006). From cultural exchange to transculturation: A review and reconceptualization of cultural 
appropriation. Communication Theory, 16(4), 474-503. https://doi.org/10.1111/j.1468-2885.2006.00277.x

Sam, D. L., \& Berry, J. W. (2016). The Cambridge handbook of acculturation psychology. Cambridge University Press.

Schwartz, S. J., Unger, J. B., Zamboanga, B. L., \& Szapocznik, J. (2010). Rethinking the concept of acculturation: Implications for theory and research. American Psychologist, 65(4), 237-251. https://doi.org/10.1037/a0019330

Sidanius, J., Cotterill, S., Sheehy-Skeffington, J., Kteily, N., \& Carvacho, H. (2016). Social dominance theory: Explorations in the psychology of oppression. In C. G. Sibley \& F. K. Barlow (Eds.), The Cambridge handbook of the psychology of prejudice (pp. 149-187). Cambridge University Press.

Stephan, W. G., Ybarra, O., \& Rios, K. (2016). Intergroup threat theory. In T. D. Nelson (Ed.), Handbook of prejudice, stereotyping, and discrimination (2nd ed., pp. 255278). Psychology Press.
Verkuyten, M. (2006). Multicultural recognition and ethnic minority rights: A social identity perspective. European Review of Social Psychology, 17(1), 148-184. https://doi .org/10.1080/10463280600937418

Ward, C., Ng Tseung-Wong, C., Szabo, A., Qumseya, T., \& Bhowon, U. (2018). Hybrid and alternating identity styles as strategies for managing multicultural identities. Journal of Cross-Cultural Psychology, 49(9), 1402-1439. https:// doi.org/10.1177/0022022118782641

Watters, S. M., Ward, C., \& Stuart, J. (2020). Does normative multiculturalism foster or threaten social cohesion? International Journal of Intercultural Relations, 75, 8294. https://doi.org/10.1016/j.ijintrel.2020.02.001

Zárate, M. A., Shaw, M., Marquez, J. A., \& Biagas, D. (2012). Cultural inertia: The effects of cultural change on intergroup relations and the self-concept. Journal of Experimental Social Psychology, 48(3), 634-645. https://doi .org/10.1016/j.jesp.2011.12.014 